\title{
Research on Bank Card Problems and Management Strategies
}

\author{
Sun $\mathrm{Hu}$ \\ Guangzhou huali science and technology vocational college
}

\author{
Chen Deyu* \\ Guangzhou school of business
}

\begin{abstract}
With the rapid development of the financial industry, banks are also followed, and now the bank card business is commonplace in our daily life. On the basis of referring to the corresponding literature, this article understands the types of bank card business, understand the positive effects it has on our work and life, and make countermeasures against the existing problems and defects of bank card business. Finally, in order to better develop bank cards, but also put forward corresponding prospects for the future.
\end{abstract}

Keywords-Bank card business; Problems; Measures; Influence; Outlook

\section{OVERVIEW OF BANK CARD BUSINESS}

The era is progressing, commercial Banks are developing, commercial banking is gradually increasing and improving, and the business includes assets business, liability business and off-balance sheet business. The off-balance sheet business is divided into traditional and innovative off-balance sheet business, traditional off-balance sheet, also known as the intermediary business, is on the basis of assets and liabilities credit business development, namely the agent to handle receipts and payments and other matters entrusted and the charge of the business.

However, intermediary business category is various, such as type of intermediary business, bank card business, agency for settlement of intermediary business, commitment and so on intermediary business, today we learn intermediate business in the bank card business.

Bank card business is commercial bank by issuing various forms of bank CARDS, management of CARDS, transfer payments, such as deposits, withdrawal, etc. The emergence and development of bank CARDS has reduced the use of cash and cheques, saving time and convenience for people's lives. At the same time, bank card enables bank service to break through time and space limit and use bank card automatic settlement and settlement system, we will be closer to a noncheck, cashless society [1].

\section{THE DEVELOPMENT OF BANK CARD BUSINESS}

Although China's bank card industry develops rapidly, it still has a big gap compared with the mature foreign bank card market. With the popularization of the bank card business, the problems are becoming more and more obvious when it is convenient for customers to consume shopping. According to our team's survey results, there are several problems in the bank card business.

\section{A. Functional problems}

At present, the bank card business functions are relatively unitary. Although the bank card business has developed rapidly in our country, many CARDS CARDS aren't the only ones that a feature that may have a card function, that is to say, in addition to ordinary bank card transfer settlement, and other functions, can also have a store gift CARDS, metro bus card, etc, but these changes are still can not adapt to the needs of different clients. In some developed countries, with the development of commodity economy and the acceleration of the degree of financial computerization, bank card and computer technology are closely combined to make the bank card much more than its original meaning. Senior bank card, besides being used as a credit voucher, comprehensive implementation of various card functions, can also have personal identification card, medical records, subway monthly ticket and other USES. If the bank card can include customer identification and other functions, the customer can only carry one card out of the door and relieve the burden of going out.

\section{B. Security issues}

With the increase of living standards, the improvement of quality of life, people's consumption amount is also rise, make a lot of customers gradually popular to use the self-service bank, for example, using an ATM, POS machine, the use of these machines in bring convenience and benefit to the customer at the same time, also brought them security problems. When customers are using a bank card, if they encounter ATM machines, they may appear to be swallowed. In addition to the machine failure, you may encounter personal information leakage problems [2]. For example, some illegal businesses, by letting customers swipe their CARDS, steal their personal information and conduct illegal trading activities. For example, many third-party payment devices now bind bank CARDS, and if the loss of bank CARDS can affect the security of alipay, WeChat, etc. 


\section{Marketing problems}

With the rapid development of China's economy, the bank card business of selling become bank staff performance evaluation criteria, this makes the bank staff in the marketing of bank CARDS, in order to amount to mark for sale at all, and use many inappropriate marketing measures. Bank card marketing measures are inappropriate in propaganda way, marketing and after-sales service are three main aspects, especially when the three can't reasonable cohesion between cause marketing disjointed phenomenon. Propaganda way the first approach is not accurate, now mainly through text ads in marketing a bank card, to issue some publicity folding single way to advertise, commitment to this kind of advertising, marketing, there are often exaggerated ingredients, it will affect bank card sales; The second is to sell the means mainly to stay at the usual counter, or simply through the means of loans, using some social relations resources to promote the sale; Finally is part of the marketing personnel for its sales bank card function is poorly understood, in the face of customers put forward some problems can't timely or accurate answers, but vague, after the products are sold, customer for its of after-sales problems cannot be resolved in a timely manner[3].

\section{Risk}

In an age when everyone has a bank card, the risk problem can't be ignored. The risk of bank card is mainly reflected in the following two aspects: firstly, the technical content of bank card is low. Now many Banks are seeking higher customer volume for one side, the cost of making CARDS is relatively low, and customers can open their CARDS and enjoy free card opening service. Manufacturing main need magnetic card read and write, and bank card program, these products on the market can get easily, plus the increasing number of computers and technology talents, criminals after get card, using some illegal technology can optionally read card, writing card and input or tamper with the password, so as to realize the magnetic stripe information of change of bank CARDS, easily alter the purpose of illegal bank card. Although now on the ATM machine, the bank added more monitoring devices, but "while the priest climbs a post, the devil climbs, while the priest climbs a post, the devil", criminals can still find all kinds of loopholes, steal the wanted information, steal their money on the card; Secondly, the cardholder's security awareness is weak, and the machine secrecy is not perfect. The security awareness of cardholders is reflected in the fact that some people earn profits by selling their bank CARDS or other bank CARDS. This inappropriate approach could result in jail time for cardholders. Then machine the imperfection of the confidentiality is otherwise reflected, for example in the recently launched in China Apple Pay of the software, don't even need to take out a bank card, customers only need to carry the iPhone can brush card. The convenience of shopping has also increased its risk. Although the criminals can't directly to steal your personal information, but when you use this function, readers can access to your personal information, if in the case of unsafe use Apple Pay may disclose personal information, and Apple Pay does not need to enter the password, need only a fingerprint can pay, so its safety is yet to be tested.

\section{MeAsures to BE RESOLVED}

\section{A. Aimed at functional problems}

Bank card in China, the problem of single function and the depth of innovation is not strong, our bank can by improving the technology, make bank card more closely linked with the daily life, can learn from western advanced Banks they advanced technology, the western commercial Banks in the innovation of the advanced tools and combining the actual situation of our country, design and develop new accord with the characteristics of China's consumer card function. Increased investment in science and technology, to employ experienced professional knowledge talent, increase the intensity of innovation, to improve the function of the bank card to reward employees, perfect the incentive mechanism, strengthen the intermediary business marketing talents cultivation, to promote the innovation of the bank card. We should also strengthen communication with other industries and establish concrete solutions to cross the bank CARDS across all walks of life. The ability to make a simple card can become unitary and reduce the burden of travel. Through internal technical improvements, more and more money will be used to make bank CARDS more useful, and people will use their CARDS more. A piece of card to cover the more various purposes, when sick in hospital, a bank card contains the user's personal service record listing information, medical records, and cost, convenient user for reimbursement, the user easier then. If on the trip, can store user's personal expressways on the road, convenient for the user to withhold fees. Bank involved in the broader, is used by the people, enhance the customer of the bank card that the cognition of intermediate business, the more conducive to the relevant bank in the share of the market.

\section{B. Addressing security issues}

In our daily life, we need to enter our personal password when we deposit and withdraw money. When the password is wrongly entered for three consecutive times, our bank card will be swallowed. The measures to effectively guarantee the safety of our bank card, at the same time, we have to rush about a bank again, to get their original bank card, it took us a lot of time and effort. On the basis of security, we can pursue more convenience. If can set up a bank card face recognition function, when forgot password, can reserve the original mobile phone number, in real time, artificial intelligence and then through the facial recognition from to get their bank card, the user will be able to save a lot of time, let the user more save worry and rest assured. In recent years, the ATM machine malfunction problems emerge in endlessly, not only because of backward technology, insufficient attention are also part of the bank's senior management, there is no timely send professional technicians to troubleshoot overhaul. If there is a problem, it needs to be solved. It is one of the important tasks for bank management to strengthen the technology improvement of ATM machine and send staff to check the potential safety problems of ATM machines. In recent years, the rapid development of third-party payment software such as WeChat payment and alipay has brought us great convenience. But if we are not careful lost our mobile phones or important documents such as id card, will bring great challenge to our security, we need to improve the security of their own money, the bank may require the user to enter bank card payment 
password, for more than two different related password input validation, drilling, to prevent criminals to steal the user's personal secret information and bring huge economic losses to users. Banks are also developing new security software, when customer lost his bank card, opened the green channel, to the user rapid blockade their bank CARDS, card funds will not be theft by outsiders. Banks should strengthen the construction of electronic information, develop and make use of information network technology, achieve the intermediary business of bank card's hardware and software environment comprehensive promotion, to provide technical support for the development of bank card,. We will increase the cooperation between Banks to realize the national network of banking and provide customers with faster and better quality products and services. The bank card business will become more and more popular, which will increase the income of bank card business [4].

\section{Aiming at marketing problems}

In the process of carrying out bank card marketing, the planning and arrangement of marketing strategy is one of the most important aspects. Subdivide the relevant market, define the market positioning, find the target of cooperation, locate the target product, and carry out the marketing work in a planned and targeted way.

First in to do a good job of marketing at the same time, find accurate propaganda way, further strengthen the propaganda work and set up propaganda booth in all operating points, make full use of field advantage of outlets for bank card in all kinds of new products, new features, new business for propaganda, let the customer can see the actual marketing results, improve the bank card card rate and utilization rate. For example: make full use of the abundant customer resources, the use of Dragon Boat Festival holiday, anniversary of the merchants, such as favorable opportunity, such as cooperate with some wellknown merchants such as Marketing Department, carry out various kinds of credit card sales and credit card rewards distinctive theme activities, such as through many campaigns, close business relations, silver activation number of bank card consumption, promote the bank card consumption directly increase greatly.

Then, we should increase the sales means, actively expand the sales channels and expand the market share. To handle the business not only in the distribution of a wide range of outlets and the form of the counter, at the same time should also organize specialized marketing operations, for door-to-door promotion work, actively look for target customers, more powerful units from the enterprise's business card to individual sports food, etc., in order to rapidly expand the scale of issuing, method to promote innovation.

Finally, customer service is an important management concept, the bank should be adhering to the principle of "everything for the cardholder", improve the marketing personnel's professional knowledge and professional quality, good service image, optimize the means of customer service, in order to enhance customer satisfaction and loyalty. Perfect customer service process, standardize the content of customer service, and change passive service to active service. In product after-sales, should analysis the relationship with individual clients, timely and accurate answer customers' question, solve the problem of customers, create value for customers, to increase customer loyalty.

\section{Addressing risks}

In the development of bank card business in China, in order to deal with the risks of bank card, we should take measures to ensure the safety of bank funds.

First of all, strictly control the opening card process, tighten the hair card link, in the process of applying for bank card, strictly follow the relevant bidding principle of bank card, regulate the business operation system of card. When filling in the application form, the applicant should provide the proof of credit, request the applicant to sign the application, scan the application form into the system, and conduct thorough investigation and verification of the applicant's data. To strictly control the bid risk and refuse to apply for any non-compliance with the relevant policies and regulations. After issuing the card, the transaction of cardholder should be monitored and managed in real time. In case of abnormal transaction, the card status of the card should be adjusted in a timely manner.

Secondly, Banks in the process of making card, at the same time, improve the credit card number should adhere to the "quality and" the guiding ideology, enhance the manufacturing cost, to improve the quality of bank card upgrade, magnetic card, speaking, reading and writing, and research and innovation program disk, strictly control quality and not let the criminals easily altered reigned. While expanding market share, avoid the number of blind and vicious competition.

Then, bank card holders should improve safety consciousness, in ATM teller machines, POS machines and other third-party payment operation, check the surrounding environment, vigilance, form an organic bank card operation process, using wireless communication technology and message information platform, to build the cardholder identity authentication system, the seamless connection with the bank card transaction processing systems, reduce the probability of problems. When business problems arise, the operation should be completed immediately and timely notify the relevant bank to solve the problem.

Finally, the management of credit risk and fraud risk should be increased, and the grading system should be applied to develop the business actively and actively develop the card market. Card issuers should strengthen the communication with other institutions, mutual cooperation, improve the machine's technical content and confidentiality, and actively participate in risk control and supervision cooperation, build up internal information communication mechanism, fully realize the risk of information sharing and counsel, strengthening the prevention of risk cases.

\section{THE DEVELOPMENT TREND OF BANK CARD BUSINESS}

The course of China's bank card business passed 20 years, has made great progress and achievements, bank card has become indispensable in people's life a financial product, although it has been penetration in China is very high, but with the development of economy and the progress of era, the development and innovation of bank card business needs, to meet the needs of the future more complex and diversified, the 
future trend of the development of basically has the following several aspects:

\section{A. Increase in bank card ownership}

Card this very convenient way to pay, can make up the cash is not safe, the disadvantage of not convenient to carry and also to a large extent, to stimulate people's consumption desire, like a credit card, people to overdraw a certain amount of consumption to meet the recent consumption desire, thereby promote economic growth; Like a savings card, people can also deposit their funds in the same time deposit interest, and there is an additional profit on the basis of the guarantee. Since bank card does bring a lot of convenience to our life, in the future days, bank card holding rate will definitely show an upward trend.

\section{B. Change of cardholder structure}

Before the debit card does not appear, the cardholder's group are mainly distributed in the high income social stratum, because at that time to deal with bank card is not only to provide proof of earnings, but also provide the bank approved by the guarantor or margin, the limit in the scope of the cardholder. With the emergence of a debit card, can satisfy people's demand of the "save first, consumption, just do card procedure itself is very convenient, high safety, low cost, with these advantages to occupy the market share, the cardholder range will gradually expand to the various social strata.

The acceptance range of bank CARDS is extended to the secondary cities and some rural areas. The characteristics of card features of rural migrant workers are developing rapidly, and the accumulative transaction amount is always high. The characteristic business of migrant workers has promoted the development of the banking industry in rural areas and promoted the development of regional economy [5].

\section{The function of bank CARDS has changed}

The main functions of the bank card is different, POS consumption, withholding of utilities, its basic function already cannot satisfy the social needs more diversified, with the rise in the rate of their bank card spending and intensity of competition in banking, bank card will inevitably to the wider market development, in order to meet the needs of modern development of a higher level. Bank card can provide a more diverse functions, like telephone banking, self-service bank, loan financing, securities transfer, booking Treasury bonds and other services, at the same time can also cooperate with other industries, in their respective resource advantages to start closer to the people to demand more favorable service.

\section{Magnetic stripe card to chip card or fingerprint to identify virtual account excessive, improve security}

Chip card with small size, large storage capacity, long service life, high safety, etc. It is not easy to be cloned to copy, so can effectively improve the safety of account, protect the security of the client money. With the permission of the technology, Banks can collect customer unique fingerprint data, produce proprietary virtual credit accounts, savings accounts or as long as customers in the businesses of fingerprint payment terminal scan fingerprint information can easily afford. Because the fingerprint has unique characteristics, it can prevent identity theft and improve security [6].

\section{E. The number of foreign transactions has soared and the proportion of foreign exchange settlement has increased}

With the rapid development of national economy, people's living standards improve, the number of going abroad and overseas consumption will increase over the previous year, significantly enhance the outbound trade fair of China bank card, the proportion of foreign exchange settlement will also increase, consumption, foreign exchange settlement for unionpay RMB, and because the interest rate of low cost, so be the first choice of the Chinese people to travel abroad of payment.

\section{F. The rapid rise of unionpay brand and fierce market competition}

In the fierce competition, the brand pattern has changed greatly. China's bank card brand mainly unionpay unionpay, VISA, mastercard, express and JCB, unionpay brand in the fierce competition, with big market share, a total of more than $50 \%$, brand advantage is very outstanding.

\section{G. The marketing mode has changed}

As a commodity, bank card also needs to use marketing to increase its users. Bank card business gradually shifted from selling goods to brand marketing, from the customer the door handle card to his door, at the same time, Banks have market commissioner, to carry out some promotional card business activities to enhance brand awareness, increasing business volume.

To sum up, through analyzing the diversity of the bank card business as well as the countermeasures of the flexibility of the implementation, the reform of commercial Banks in handling and bank card business process more smoothly, reduce barriers, accumulate experience, in the face of known and unknown risks, more cool.

\section{REFERENCES}

[1] Zhou and li Lin: the impact of diversified income structure of Chinese commercial Banks on the risk of Banks, international financial research, May 2017.

[2] Xu aijun: a brief discussion on business risk supervision of commercial Banks, financial economy, March 2017.

[3] Dai guoqiang: commercial bank management, education press, 2004.

[4] Liu mengfei, zhang xiaolan, zhang chao: research on diversification, operation performance and risk correlation of commercial Banks in China, international financial research, 08, 2016.

[5] Qiao xueli: a study on diversification of commercial Banks and correlation between performance and risk, China business, 2013, 19.

[6] Lian ping: middle business of 21st century commercial Banks, China finance press, 2014 edition. 